\title{
MATURAÇÃO AUDITIVA CENTRAL \\ E DESENVOLVIMENTO DO BALBUCIO EM CRIANÇAS USUÁRIAS DE IMPLANTE COCLEAR
}

\author{
Mabel Gonçalves Almeida ${ }^{(1)}$, Dóris Ruthi Lewis ${ }^{(2)}$
}

Os Programas de saúde auditiva têm se estruturado no sentido de garantir a identificação precoce da perda auditiva por meio dos programas de Triagem Auditiva Neonatal e dos serviços de alta complexidade voltados para o diagnóstico audiológico e intervenção terapêutica precoce. Os apareIhos de amplificação sonora individual e ou implante coclear são as principais ferramentas utilizadas para a (re) introdução da estimulação acústica /elétrica, essenciais para o desenvolvimento da linguagem oral.

No entanto, os investimentos governamentais com as políticas públicas em saúde auditiva precisam ser justificados, o que faz crescer a necessidade de se fornecer dados sobre os resultados dessa intervenção no que concerne a inserção social dessas crianças.

O cenário científico mundial volta-se então para a pesquisa de técnicas e procedimentos capazes de verificar as mudanças ocorridas no sistema nervoso auditivo central (SNAC) após a estimulação precoce e sua relação com o desenvolvimento dos padrões linguísticos. Os potenciais evocados auditivos corticais inserem-se nesse contexto, pois alguns de seus componentes são considerados biomarcadores da maturação dos padrões auditivos centrais ${ }^{1}$ e são capazes de inferir sobre as mudanças neurofisiológicas ocorridas após a intervenção, bem como

(1) Fonoaudióloga colaboradora do Centro "Audição na Criança" da Divisão de Educação e Reabilitação dos Distúrbios da Comunicação da Pontifícia Universidade Católica de São Paulo, CeAC/DERDIC/PUCSP, São Paulo, SP, Brasil; Mestre em Fonoaudiologia pela Pontifícia Universidade Católica de São Paulo; Doutoranda do Programa de Estudos Pós-Graduados em Fonoaudiologia da Pontifícia Universidade Católica de São Paulo.

(2) Fonoaudióloga do "Centro Audição na Criança" da Divisão de Educação e Reabilitação dos Distúrbios da Comunicação da Pontifícia Universidade Católica de São Paulo, CeAC/DERDIC/PUCSP, São Paulo, SP, Brasil; Professora Doutora Titular da Pontifícia Universidade Católica de São Paulo, PUC, São Paulo, SP, Brasil; Professora da Faculdade de Fonoaudiologia e do Programa de Estudos Pós-Graduados em Fonoaudiologia e Centro Audição na Criança, PUC, São Paulo, SP, Brasil; Doutora em Saúde Pública pela Universidade de São Paulo.

Conflito de interesses: inexistente inferir sobre o desenvolvimento das habilidades auditivas.

Dessa forma, esses potenciais podem ser utilizados clinicamente, para de forma objetiva, verificar se os dispositivos eletrônicos estão fornecendo estimulação acústica/elétrica suficiente, capaz de provocar mudanças no sistema auditivo central, observadas nas latências dos componentes corticais, principalmente na latência da onda P1.

$\mathrm{O}$ artigo intitulado "Central Auditory Maturation and Babbling Development in Infants With Cochlear Implants" de autoria de Anu Sharma e colaboradores $^{2}$ traz informações clínicas importantes a cerca da relação existente entre a maturação dos padrões auditivos centrais e o desenvolvimento dos balbucios em crianças após a (re) introdução da estimulação auditiva. Nesse artigo, os autores examinaram, em estudo longitudinal, as mudanças ocorridas na latência do componente P1 dos potenciais auditivos corticais, e sua relação com o desenvolvimento das vocalizações, em duas crianças que receberam o IC multicanal, por volta dos 13 a 14 meses de idade. O registro de P1 foi gravado em resposta ao estímulo de fala /ba/, antes do implante coclear, e em alguns períodos posteriores ao mesmo.

O registro das vocalizações foi realizado nos mesmos períodos que os do PEALL e enquanto as crianças interagiam com seus "cuidadores". Antes do implante foram gravadas duas sessões separadas por um período de duas semanas. Após o implante, as sessões foram gravadas uma vez ao mês, por aproximadamente 45 minutos. Os registros foram transcritos, e foram analisadas em 13 categorias usando um sistema de transcrição, com verificação acústica. As categorias 1 a 8 foram classificadas como vocalizações precanônicas, e de 9 a 12 foram classificadas como canônicas.

Os tempos para o registro de cada sessão, tanto para as medidas eletrofisiológicas quanto para as vocalizações, foram diferentes entre os sujeitos. Para o sujeito 1, os registros eletrofisiológicos e as vocalizações foram realizados em um maior número de períodos. Provavelmente o maior tempo de observação das respostas da criança 1, na opinião 
dos autores, deve-se ao fato de que essa criança foi diagnosticada apenas aos 7 meses de idade, o que aumentou o tempo de privação sensorial e poderia influenciar na latência da onda $\mathrm{P} 1$, enquanto que a criança 2 foi identificada com perda auditiva logo após a triagem auditiva.

O estudo mostrou que as crianças alcançaram latências dentro do padrão normal em até três meses após o implante coclear, considerando 95\% de intervalo de confiança para o desenvolvimento normal da latência de $\mathrm{P} 1$, obtidos por Sharma et al $(2002)^{3}$. Os valores de latência da onda P1 foram sistematicamente menores, em todos os períodos avaliados, para o sujeito 2. Este achado pode estar relacionado ao fato de que essa criança teve um menor tempo de privação sensorial, com maior tempo de estimulação acústica, fornecida pelo AASI anteriormente ao implante coclear.

As produções de fala observadas antes do IC, progrediram também dentro de três meses, demonstrando padrões consistentes de aquisição de vogais, consoantes e enunciações de sílabas. Assim, os autores sugerem que o desenvolvimento da respostas da latência de $\mathrm{P} 1$ e o desenvolvimento dos comportamentos comunicativos podem seguir uma trajetória de desenvolvimento similar.

Portanto, o estudo traz evidências de que quanto mais cedo acontecer a identificação, o diagnóstico e a intervenção em crianças com perdas auditivas permanentes, melhor será a resposta do sistema nervoso auditivo central à estimulação auditiva, e consequentemente, mais rápido acontecerão as primeiras produções vocais, melhorando o comportamento comunicativo. Além disso, essas informações podem ser obtidas por meio da observação das mudanças na latência da onda P1 dos potenciais corticais, de forma confiável e objetiva.
Nacionalmente, os potenciais auditivos corticais já vêm sendo utilizados com sucesso na avaliação dos aspectos cognitivos e das habilidades auditivas centrais, em crianças e adultos com perda auditiva e com outras patologias. No entanto, a utilização desses potenciais para a avaliação da maturação dos padrões auditivos centrais e, consequentemente, dos benefícios fornecidos pelos dispositivos eletrônicos em crianças muito pequenas ainda é um desafio.

Dessa forma, estudos nacionais utilizando esse procedimento são essenciais na tentativa de fornecer dados e evidências relacionadas aos benefícios ocasionados pela introdução precoce da estimulação acústica / elétrica e assim justificar os atuais programas de identificação e intervenção precoce de perdas auditivas em neonatos e lactentes, bem como atrair novos fomentos governamentais para a melhor estruturação e suporte dos serviços de alta complexidade em saúde auditiva.

\section{REFERÊNCIAS}

1. Dorman MF, Sharma A, Gilley P, Martin K, Roland $P$. Central auditory development:Evidence from CAEP measurements in children fit with cochlear implants. Journal of communication Disorders. 2007; 40:284-94.

2. Sharma A, Emily Tobey, Michael Dorman, Sneha Bharadwaj, Kathryn Martin, Philip Glley, Fereshtch Kunkel. Central Auditory Maturation and Babbling Development in Infants With Cochlear Implants. Arch Otolaryngol Head Neck Surg. 2004;130:511-6 3. Sharma A, Dorman M, Spahr T. A sensitive period for the development of the central auditory system in children with cochlear implants. Ear Hear. 2002;23:532-9.

Endereço para correspondência:

Mabel Gonçalves Almeida

Rua Marquês de Itu, 836 apt 75

São Paulo - SP

CEP: 01223-000

E-mail:mgafono@yahoo.com.br 